\title{
UM SONHO DIVINO NÁO CONDENSADO: FILOSOFIA E LITERATURA EM TEIXEIRA DE PASCOAES
}

\section{A DIVINE DREAM NOT CONDENSED: PHILOSOPHY AND LITERATURE IN TEIXEIRA DE PASCOAES}

\author{
Maria Celeste Natário \\ Instituto de Filosofia da Universidade do Porto, Porto, Portugal
}

Resumo: Procuraremos, neste texto, desenvolver a concepção poética e metafísica de Teixeira de Pascoaes, entre Filosofia e Literatura.

Palavras-Chave: Teixeira de Pascoaes; Filosofia; Literatura.

Summary: We seek, in this text, develop the poetic and metaphysical conception of Teixeira Pascoaes, between Philosophy and Literature.

Key-words: Teixeira Pascoaes; Philosophy; Literature.

“o mundo é o homem feito de terra e céu, de física e metafísica e de outros elementos ignorados, não do nosso ser, mas da nossa inteligência"

(PASCOAES, 1993, p. 54).

"por metafísica designa-se não só e apenas o que está para além do físico, mas antes e primordialmente o que lhe é íntimo e nele se supóe” (MARINHO, 1945, p. 133).

A revelação do sentido mais profundo da existência humana e do mundo foi, durante séculos, missão da metafísica. No último século, com o papel que, entretanto, a ciência foi assumindo e, cumulativamente, com o progressivo prestígio, ainda sob o influxo da crítica kantiana, das filosofias empíricas, o panorama alterou-se, tornando-se o pensamento humano, hoje, cada vez mais anti-metafísico. Aliás, essa foi também o "veredicto" de Martin Heidegger, provavelmente o filósofo mais decisivo do último século.

A Filosofia, tanto hoje quanto ontem, não pode ser indiferente à crítica kantiana da metafísica - apesar dos Prolegômenos a toda a metafísica futura, em que se deixa a porta aberta para uma "metafísica moral" -, e a tudo o que desta, direta ou indiretamente, decorreu. Mas, ao mesmo tempo, importa regressar à filosofia grega, em que o desvelamento da natureza primordial do cosmos, partindo da Natureza e nela se inspirando, procuram 
na physis - primeiro pela sua contemplação, mas também pelo desejo e necessidade - uma resposta ou respostas capazes não só de responder à pergunta pela "origem", mas também algo que explicasse a dualidade, assim cumprindo o desiderato da unidade e da harmonia. E foi essa sabedoria que, para nós, se tornou indispensável e é parte do início do caminho, que se tornou longo, aparentemente interminável.

Depois dos pré-socráticos, importa aqui referir, para além de Platão, a figura de Aristóteles, o qual apresenta uma concepção de Filosofia que se caracteriza, desde logo, pela sua integralidade. Nele, a Filosofia é, simultânea e indissoluvelmente, conhecimento do ser e realização do humano, ao mesmo tempo que nele, há, também, uma noção de "física", physis, que transcende a posterior oposição entre física e metafísica...

Mas o nosso horizonte neste ensaio é, acima de tudo, o pensar e sentir de Teixeira de Pascoaes, o poeta da comunhão e celebraçáo da natureza e da vida, o poeta que parece aceder por inteiro à essência da realidade, tornandose interior a ela mesma, e cuja expressão é a identificação com o cosmos, a palavra que é meio e, simultaneamente, parte da substância, da sua obra e da sua concepção poético-filosófica. Pensar e sentir radicados na montanha, na luz e nas sombras, aí onde os seus versos, a sua prosa, as imagens e as paisagens, pelo seu gênio literário criadas, terão que ser compreendidos. É aí também, à luz de uma inspiração às vezes dolorosa e sempre, ou quase sempre, divina, que se enraíza a verdade e a solidez da sua arte, feita de versos e prosas, cujas notas musicais sáo, também, o sinal de uma poesia de afirmação profético-mística.

$\mathrm{Na}$ sua paisagem de matéria viva, exaltada e humilde, todos os recortes são densos, mesmo que, às vezes, os montes sejam arredondados e amenos. De modulaçôes suspensas é o seu sombreado, que não resulta de estáticas sombras, mas de uma vivência do que pode chamar-se uma herética religiosidade, de intuiçôes e impulsos, cuja densidade de profundos sulcos nos conduz a uma paisagem que é a do Poeta, e, por isso, por ele transformada.

A direção e o sentido da sua cósmica relação, exaltada e apaixonada, visam, tanto no começo como no fim, a harmonia. "Naturalmente" espontânea é a sublimidade e o magnetismo da sua arte, da sua filosofia da natureza, que, a nosso ver, umedece a retina do olhar, mas também pelo sentimento de emanaçáo revelada e visionária, a que as sombras e a luz da obra de Pascoaes nos eleva. A relevância da realidade na construção metafísica pascoaesiana tem, pensamos, algo de determinante e fundamental - esse algo é a própria "física", no sentido grego em geral e aristotélico em particular, 
já aqui referido -, pois a metafísica deixa-se descobrir na matéria, já que todos os fenômenos só o seráo quando dados à análise da consciência. Nas palavras de Pascoaes, "o ser é uma síntese das coisas" (PASCOAES, 1993, p. 9), que espelha uma só imagem no espírito, a partir da sua "complexidade fenomenal".

José Marinho, um dos mais insignes hermeneutas do poeta do Marão, definiu a metafísica como "não só e apenas o que está para além do físico, mas antes e primordialmente o que lhe é íntimo e nele se supóe" (MARINHO, 1945 , p. 133), não se afirmando, por isso, o metafísico por negação do físico. Muito pelo contrário, o metafísico afirma-se por "apoteose" do físico. Daí, em Pascoaes, a celebração da Natureza, de todo o Cosmos, no qual ele encontra o metafísico - nas estrelas e também nas montanhas, nas árvores, nas pedras...

No entanto, não se podendo classificar de um modo geral o pensamento de Pascoaes como "dialético", existe uma dialética intermitente entre o material e o imaterial, sendo uma síntese dessas duas vertentes o homem e, mais propriamente, a sua atividade espiritual. Segundo o nosso autor, o Cosmos procede num movimento de "dentro para fora", isto é, do imaterial para o material, sendo a matéria o ponto de partida para o conhecimento da essência. É a partir desse movimento que o cientista procurará a fixação do mesmo, ou, dito de outra forma, procurará estabelecer regularidades, o que, segundo Pascoaes, torna a visão científica necessariamente incompleta, classificando-a como "absurda", por jamais se situar numa visão fixista ou cousista, como diria Leonardo Coimbra, de um Cosmos eternamente dinâmico. Pelo contrário, só o Poeta terá a capacidade da percepção do carácter permanentemente ativo e criador do Universo.

A essência estende-se em matéria na mesma medida em que a alma se projeta em corpo, daí se podendo inferir uma relação de movimento inverso entre cosmos e conhecimento: se o primeiro procede do náo material para o material, o homem conhece a essência a partir da realidade fenomênica, a partir do que ele é, do que ele sente, face à natureza e às coisas que o rodeiam, aquelas mesmas coisas que, afinal, são as sombras, que o poeta vai encher de vida, até mesmo de excesso, por essas representarem o reflexo de algo que para além delas está... Será que se pode perguntar ser possível "existir" Pascoaes sem aquilo que ele diz ser que não era o que é? Eis a resposta do Poeta, no poema Canção duma sombra: 
Ah, se não fosse a névoa da manhã

E a velhinha janela, onde me vou

Debruçar, para ouvir a voz das cousas,

Eu não era o que sou.

Se não fosse esta fonte, que chorava,

E como nós cantava e que secou...

E este sol, que eu comungo, de joelhos,

Eu não era o que sou.

Ah, se não fosse este luar, que chama

Os espectros à vida, e se infiltrou,

Como fluido mágico, em meu ser,

Eu nâo era o que sou.

E se a estrela da tarde não brilhasse;

E se não fosse o vento, que embalou

Meu coração e as nuvens, nos seus braços,

Eu não era o que sou.

Ah, se não fosse a noite misteriosa

Que meus olhos de sombras povoou,

E de vozes sombrias meus ouvidos,

Eu não era o que sou.

Sem esta terra funda e fundo rio,

Que ergue as asas e sobe, em claro voo;

Sem estes ermos montes e arvoredos,

Eu não era o que sou.

Ora, em Pascoaes, essa celebração da natureza é, em última instância, uma filosofia da natureza. Vejamos, por exemplo, o poema Marânus:

O que é a natureza? É qualquer cousa que não sendo matéria nem espírito, na sua evoluçâo misteriosa,

toma formas de espírito e matéria...

(PASCOAES, 1972, p. 208).

No canto XI, ainda do mesmo poema, "Marânus, a Saudade e Dom Quixote", está presente um lirismo diáfano, ao mesmo tempo que se pressente o vivido e lembrado na memória saudosa. Diz Marânus a Quixote, no final do canto, dando também e talvez do próprio Pascoaes uma boa "definição": 
Olhando sismático a Saudade:

O meu fim é velar por esta virgem;

Santificado corpo, onde germina

A glória do meu Povo e o seu futuro,

Uma nova esperança que é divina

(PASCOAES, 1972, p. 248).

[...]

Pois tudo, tudo há-de passar, enfim,

O homem, o próprio mundo passará

Mas a Saudade é irmã da Eternidade"

(PASCOAES, 1972, p. 303).

Esta visão - da Natureza, do Mundo, do Ser -, estando presente em Marânus (1910), desenvolver-se-á, também, em Regresso ao Paraíso (1912). Aqui, Pascoaes fala da reconquista do Paraíso realizada pelo esforço do Homem, que é o Eterno Adáo, e a sua Eva. Poema verdadeiramente religioso, Regresso ao Paraíso foi visto por Leonardo Coimbra, conforme podemos ler nas páginas d'A Águia, como a "Bíblia Lusitana". Esse sentido religioso iremos encontrá-lo, no seu clímax, na obra Sáo Paulo, em que escreve:

A Religiāo interessa-me como Revelação instintiva ou consciente (poesia pura e ciência pura); e não como regra de conduta. Deus não está nos preceitos de Moral, que é de origem social, um produto da vida em comum. Deus é, além de tudo, o Espírito criador; e o homem, antes de tudo, é o ser (PASCOAES, 1984 , p. 16, grifo do autor).

Por razões endógenas e exógenas, no percurso de Pascoaes sentese a sua clara percepçáo relativamente às mudanças que no mundo iam acontecendo, sobretudo a partir da década de trinta, denotando, nesse percurso, uma extrema coerência. Para além de todas as "voltas do mundo", para além mesmo da mudança de perspectivas - Pascoaes, a certa altura, quase deixa de escrever poesia e passa a escrever em prosa -, há, de fato, essa coerência extrema. Decerto, uma coerência não estática, mas dinâmica, que foi integrando, inclusive, as maiores inovaçôes científica da época - como, por exemplo, as que decorrem da nova física de Heisenberg, de que Pascoaes foi estando a par através do seu grande amigo e conterrâneo amarantino Ilídio Sardoreira.

Havendo uma coerência assinalável em todo o percurso de Pascoaes, em cada obra sua podemos encontrar espelhada a integralidade do seu pensamento - como, na sua visão poeticamente holística, numa simples pedra poderíamos encontrar espelhada a integralidade de todo o Universo. 
Ainda assim, há, decerto, algumas obras que espelham, senão mais, pelo menos melhor essa integralidade do seu pensamento. Entre elas, a nossa escolha recai sobre O Homem Universal (PASCOAES, 1993), de que citaremos e comentaremos alguns excertos. Logo no primeiro capítulo, atentemos nesta passagem:

\begin{abstract}
A vida é a morte da matéria, que se esvai, quando entre ela e o Vácuo se estabelece a menor distância. Desaparece pelos seus extremos reduzidos à mínima densidade decrescente. O mínimo menos alguma coisa é igual a nada. Atingimos o Nada, a Unidade, a Divindade. Mas temos de admitir o nada cheio de tudo, a unidade cheia de variedade, o simples muito complexo e a divindade em farrapos humanos e desumanos. Atingimos o absurdo natural, o lógico paradoxo, em que a Existência a si mesma se desvenda, por intermédio da nossa alma (PASCOAES, 1993, p. 10, grifo do autor).
\end{abstract}

Nessa passagem, em que se equaciona a vida à luz de dois extremos contrapolares - a matéria e o seu contrapolo extremo: "o Nada, a Unidade, a Divindade" - percebemos, logo, uma vez mais, a relação entre física e metafísica, em que essa designa "não só e apenas o que está para além do físico, mas antes e primordialmente o que lhe é íntimo e nele se supóe" (MARINHO, 1945, p. 133), para recorrermos de novo às palavras de Marinho.

No início do segundo capítulo da referida obra, observa Pascoaes o seguinte:

A ordem é a própria força criadora ou transformadora do abstracto em concreto, do espaço em matéria, do imponderável infinito em finitos ponderáveis. Esta força é o mesmo espírito divino revestindo-se de plásticos relevos inanimados e animados (PASCOAES, 1993, p. 11).

Pode aqui constatar-se que, se a terminologia vai variando, a ideia central permanece a mesma, isto é, a matéria nada mais é do que a cristalizaçáo do espírito e o espírito nada mais é do que a sublimação da matéria. $\mathrm{Ou}$, em outros termos, o físico é a cristalização do metafísico e o metafísico a sublimaçáo do físico. E por isso pode Pascoaes falar de "um negativo imaterial a afirmar-se materialmente" (PASCOAES, 1993, p. 12), ou dizer-nos que "é através da matéria que o imaterial negativo se torna positivo ou animado" (PASCOAES, 1993, p. 18).

Com efeito, não há no poeta-filósofo uma visão efetivamente negativa da matéria ou do físico - desde logo, porque não há matéria que não esteja já entranhada de "espírito", como não há física que não esteja já entranhada 
de metafísica. E por isso transcende Pascoaes todas as visóes dicotômicas ou maniqueístas, sempre redutoras, por isso mesmo, anti-filosóficas, por mais que se auto-intitulem "filosóficas". Não, em Pascoaes, a matéria e o espírito, a física e a metafísica, não são, de modo algum, contrários, mas, tão só, complementares. Daí que, ainda e sempre, para Pascoaes, o "homem integral" não seja apenas espiritual ou metafísico - nas suas palavras:

O homem integral é o ser físico e metafísico, que existe desde a raiz à folha e ao perfume, se compararmos a Criação a uma árvore, a um organismo transformador de imateriais invisíveis no maravilhoso espectáculo das coisas! E são elas que contemplam através dos nossos olhos. Adquirem, em nós, a sua actividade espiritual, transcendente e imanente, em reflexão sobre si mesma ou sobre o panorama exterior. Esta actividade é o ponto central e crucial de todas as energias naturais - a sua unidade permanente, a alma humana (PASCOAES, 1993, p. 20, grifo do autor).

Daí, também, a sua concepção de homem "artista" - aquele que se aproxima mais do seu conceito de homem "integral": "Quem não for cão pelo nariz e burro pelas orelhas, e não tiver uns olhos de andorinha, folhas e raízes de árvore, será tudo menos um artista" (PASCOAES, 1993, p. 36) -, nele se espelhando a integralidade do Universo, sobre o qual interroga e observa:

O universo é um simples Como, sem Porquê? nem Para quê? um tudo igual a um Nada? E deste Nada igual a tudo surgiu o homem, feito de carne feroz e sombra meditativa. E o nada da sua carne feroz é o tudo da sua sombra meditativa. É imagem e espelho, mas na imagem é que a ilusão da vida se incendeia. É um retrato desenhado ou contido na sua consciente definição. Esta imagem anímica, senhora sua, apropria-se do mundo, porque o encontra dentro de si mesma, como se encontra dentro dela. A alma vive entre a matéria demoníaca e o espírito divino, entre a criação e a redenção, entre o sólido, que é a entrada na Existência, e o gasoso, que é a saída. E estando no centro das coisas, envolve-as, de longe, dispondo-as num Todo harmônico (PASCOAES, 1993, p. 41, grifo do autor).

Por que tudo está em tudo, "não há zero absoluto, vazio absoluto, nem Deus só Deus” (PASCOAES, 1993, p. 51), pois o espírito está sempre já na matéria e a metafísica está sempre já na física. Na sua mais estreme materialidade, o próprio homem é sempre já um ser espiritual. Esta dimensão - a espiritual ou metafísica - não se afirma, com efeito, na negação daquela - da física ou material. Daí que até a sexualidade humana seja em Pascoaes valorizada como "a própria substância da criatura, o seu dinamismo biológico", referindo-se ainda ao "corpo do desejo", à 
"matéria autêntica das coisas", "a encarnação do verbo, a sombra a ganhar plasticidade" (PASCOAES, 1993, p. 53). Na medida em que reconhece tudo isso dentro de si, o homem reconhece-se como "integral". Nesse limite, porém, o homem, "sendo o mundo", excede-o:

O animal excede o vegetal, e este, o mineral. E o homem, sendo o mundo, excede o mundo, para o definir, ou abranger em pensamento. Assim, o mundo é o homem feito de terra e céu, de física e metafísica e de outros elementos ignorados, não do nosso ser, mas da nossa inteligência (PASCOAES, 1993, p. 53-54).

Mas, só mediata e processualmente, a inteligência o descobre, aquilo que o nosso ser já sabe desde sempre, pois, como escreveu:

[...] o homem é, em si mesmo, neste cogito cartesiano em que ele se espiritualiza, espiritualizando ou definindo o existente. O homem é a definição do Indefinido. Considera-se, portanto, um indivíduo perfeito ou acabado ou limitado; e pela mesma razáo, vê o Cosmos como um Todo harmonioso, esférico, ou complexo de curvas que se fecham, guardando o maior espaço dentro delas (PASCOAES, 1993, p. 57, grifo do autor).

Para Pascoaes, é o próprio homem "integral” a ponte maior entre matéria e espírito, entre física e metafísica, porquanto "dentro da existência o homem participa do mineral; e, fora dela, participa do divino" (PASCOAES, 1993, p. 64). Daí, também, a forma como Pascoaes vê a relação entre o homem e Deus:

O homem está separado de Deus e unido. O homem e Deus! A razão e o absurdo! Mas se Deus não fosse um absurdo, quem lhe ligaria importância ou acreditaria nele? Quem se atreveria a adorá-lo ou a negá-lo? Só amamos o absurdo e o impossível! E há nisto um grande sinal. É que o impossível pode deixar de o ser... Não ignoramos os limites do possível ou todas as virtudes da matéria? (PASCOAES, 1993, p. 65).

E daí, de fato, toda a tarefa do homem: realizar Deus - ou, como aqui nos diz Pascoaes, ser "a consciência da Criação e do Criador" (PASCOAES, 1993, p. 76). No homem integral se realiza a máxima harmonia entre matéria e espírito, entre física e metafísica, afirmando o nosso autor:

No homem universal, atingem uma expressão harmoniosa os seus elementos físicos e metafísicos, o espírito e a matéria: - o espírito, essa constante na inconstância, porque ele condensa em presente duradouro e tempo volátil e 
concentra, em si, a Imensidade (PASCOAES, 1993, p. 99, grifo do autor). Aparecendo o homem, no Epílogo de O Homem Universal, como a "suprema expressão consciente ou sintética da Natureza (PASCOAES, 1993, p. 113).

No entanto, para Pascoaes, a Natureza é muito mais do que a "mera natureza”. $\mathrm{Na}$ sua reflexão, ecoam as perplexidades dos antigos gregos: o que é que permanece antes de tudo? Qual o primordial a partir do qual tudo provém? Qual a sua gênese? Do Caos? Do indiferenciado (apeiron) primordial que é diferenciação originária? $\mathrm{Na}$ conhecida passagem da Teogonia, de Hesíodo, afirma-se, primeiro, que tudo surgiu do Caos... Em Pascoes, pode afirmar-se algo de análogo, ainda que o seu "enraizamento" de algum modo o leve a uma irredutibilidade do Caos, pelo que, se por um lado a natureza e o seu "enraizamento" o deixa de algum modo sem saber o que está antes do Princípio manifestativo - e é aí que toda a sua criação poética jorra, é aí que o seu alimento está e a partir do qual ele diz ser o que é -, por outro lado, no princípio como no fim, pode estar "Tudo" e "Nada", porque para ele o Nada pode ser "a alma de tudo" (PASCOAES, 1993, p. 61). Estamos face a uma dimensão poética em que as relaçóes com o Universo, com a Natureza, sendo manifestativas, apresentam-se de certo modo falsas e autênticas e, nessa medida, nos colocam perante a ideia de uma espécie de "identidade misteriosa" (PASCOAES, 1993, p. 120-121), que igualmente indicia uma concepção de um Nada cheio de Tudo... E o que será um Nada cheio de Tudo? Qual será a luz, a claridade, desse Nada cheio de Tudo? Essa luz, essa claridade, pode ser, em Pascoaes, uma "soberana solidáo". E é ela que o faz escrever. E ela é o que escreve, tanto quanto isto pode dizer-se. Espectador da sua intimidade, Pascoaes vive entre um real irreal e um ideal que não encontra, mas do qual decerto se alimentou ele e sua obra, mesmo que «sonâmbulo às escuras», porque, como diz:

A vida é o sonho de um pobre tolo, um fumo a sair duma caveira... Tudo é sonho de um pobre tolo... somos um sonho divino que não se condensou, por completo, dentro dos nossos limites materiais. Existe, em nós, um limbo interior; um vago sentimental e original que nos dá a faculdade mitológica de idealizar todas as coisas... (PASCOAES, 1973, p. 19). 


\section{Referências}

MARINHO, José. O Pensamento Filosófico de Leonardo Coimbra. Porto: Figueirinhas, 1945.

- Verdade, Condiçáo e Destino no pensamento português contemporâneo. Porto: Lello, 1976.

PASCOAES, Teixeira de. As Sombras/ Senhora da Noite/ Marânus. "Obras Completas", III, introd. e aparato crítico por Jacinto do Prado Coelho. Lisboa: Livraria Bertrand, 1972.

O Pobre Tolo/ versáo inédita. "Obras Completas", IX, introd. e aparato crítico por Jacinto do Prado Coelho. Lisboa: Livraria Bertrand, 1973.

. Sáo Paulo. Apresentaçáo de Antônio Pedro de Vasconcelos. Lisboa: Assírio \& Alvim, 1984.

. O Homem Universal e outros escritos. Fixação do texto, prefácio e notas de Pinharanda Gomes. Lisboa: Assírio \& Alvim, 1993. 